\title{
Change in Kinetics and Kinematics during 1-Footed Drop Landing with an Increase in Upper Body Weight
}

\author{
Jin-Taek Lee ${ }^{1} \cdot$ O'Sullivan David $^{2}$ \\ ${ }^{1}$ Korean Sports Council, Seoul, Korea \\ ${ }^{2}$ Department of Sport Science, College of Sports Science, Chungang University, Anseong, Korea
}

Received 31 October 2010; Received in revised form 8 December 2010; Accepted 7 March 2011

\begin{abstract}
The purpose of this study was to investigate changes in kinetic and kinematic variables associated with an increase in upper body weight. Eighteen healthy male university students(175.96 $\pm 4.19 \mathrm{~cm}, 70.79 \pm 8.26 \mathrm{~kg})$ participated. Eight motion analysis cameras(Qualysis Oqus 500) and 2 force AMTI platforms(Advanced Mechanical Technologies Inc. OR6-7, US) were used to record motion and forces during the drop landing at a frequency of $120 \mathrm{~Hz}$ and $1200 \mathrm{~Hz}$, respectively. QTM software(Qualisys Track Manager) was used to record the data, and the variables were analyzed with Visual 3D and Matlab 2009. For the drop landing, a box of $4 \times 2 \times 0.46 \mathrm{~m}$ was constructed from wood. Knee and ankle maximum flexion angle, knee flexion angle, knee and ankle angle at landing, time for maximum ankle flexion after landing, and time for maximum knee flexion after landing were calculated. There was a significant change in the time for maximum and minimum ground force reaction and the time for maximum dorsal flexion after landing $(p<.05)$ with increasing weight. There was no significant change for the hip, knee, and ankle ROM, whereas there was an increase in the angle ROM as the weight increased, in the order of ankle, knee, and hip ROM. This result shows that the ankle joint ROM increased with increasing weight for shock attenuation during the drop landing. There was a trend for greater ankle ROM than knee ROM, but there was no clear change in the ROM of the hip joint with increasing weight. In conclusion, this study shows the importance of ankle joint flexibility and strength for safe drop landing.
\end{abstract}

Keywords : Drop Landing, Weight, Kinematics, Kinetics

\section{I . Introduction}

In sports and during daily activities the frequency of landing on one foot is very high. Drop landing is defined as the motion of a person who free falls down and lands on a surface below. For a successful and safe landing the person is to reduce the kinetic energy formed during the free falling in a manner that is slow enough not to cause injury or overloading to joints and muscles in the lower limbs. Here there is a transfer of energy from the lower limbs to the trunk.

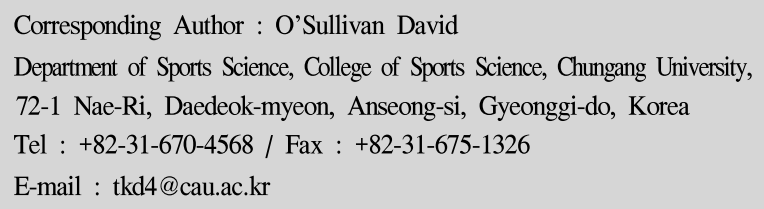

With the importance of the ability of someone to be able to deal with drop landing(Dufek \& Bate, 1991; Frobell et al., 2008; Johnson, 2003; Kirkendall \& Garrett, 2001) there have been studies investigating the various heights of drop landing and its influence. Zhang(2003) studied the effects of heights between 0.32 and $1.03 \mathrm{~m}$ on the motion of the drop landing while in a similar study Mxcaw(2003) focused on the kinetics I.e. the maximum vertical forces.

During the drop landing Hewett \& Colleagues(2005) reported that one of the factors of injury to the anterior and posterior cruciate ligament and knee area was due to the inability of players to deal with drop landing effectively and that there were sudden increases in the varus forces. It is reported(Mascaro, T. B., \& Swanson, 1994) that during outdoor sports between 10-30\% of lower limb injuries are to the ankle joint, and for indoor sports this increases to approximately $45 \%$. 
In Korea, there has been many studies (Cho, Kim, Moon, Cho \& Lee, 2010; Choi et al., 2006; Jo et al., 1998; Jo, 1999, 2004; Kim, Kim \& Kim, 2010; Lee, Lee \& Choi, 2001; Yu \& Lim, 2008) focusing on different aspects involved in the drop landing. Recently Jo(2010) has reported on the effect of the difference in motion of the drop landing and how it can affect abduction and adduction at both the knee and ankle joints. It also described the need for powerful knee flexors to maintain a safe landing.

In Kim(Kim et al., 2010) and Cho's(Cho et al., 1998, 1999, 2004) studies they discuss the way that height affects the drop landing motion while Choi(2006) researches about how the effects of a varying backpack load can change the kinetic and kinematic variables. In our daily routines we tend to carry things in front of our trunk and therefore the difference in loading area merited further research. The purpose of this study was to investigate both the change kinetic and kinematic variables according to the increase in upper body weight to observe an effective landing method.

\section{Research Methods}

\section{Subjects}

18 male university students without any musculoskeletal problems in the last year in their twenties were selected as subjects for this study. The subjects height and weight were as follows; 175.96 $\pm 4.19 \mathrm{~cm}, 70.79 \pm 8.26 \mathrm{~kg}$. After explanation and signature of the consent forms the experiment begun.

\section{Experimental Equipment}

Table 1. Equipment

\begin{tabular}{cccc}
\hline & $\begin{array}{c}\text { Name of } \\
\text { Equipment }\end{array}$ & Quantity & Software \\
\hline \hline Motion Analysis & $\begin{array}{c}\text { Qualisys } \\
\text { Oqus 500 }\end{array}$ & 8EA & $\begin{array}{c}\text { Qualisys Track } \\
\text { Manager }\end{array}$ \\
\hline $\begin{array}{c}\text { Ground Reaction } \\
\text { Force }\end{array}$ & AMTI OR6-7 & 1EA & $\begin{array}{c}\text { Qualisys Track } \\
\text { Manager }\end{array}$ \\
\hline Post Processing & - & 2EA & $\begin{array}{c}\text { Visual 3D } \\
\text { Matlab 2009 }\end{array}$ \\
\hline
\end{tabular}

The three dimensional coordinates of the reflective markers was calculated and recorded at $120 \mathrm{~Hz}$ by 8 infra-red cameras(Qualysis Oqus 500). For the kinetics an AMTI force platform(Advanced Mechanical Technologies Inc. OR6-7, US) was used and recorded at $1200 \mathrm{~Hz}$. Both kinetic and kinematic data were controled by
QTM(Qualysis Track Manager) and the kinetic data was acquired by the Qualysis USB-2533 A/D Board System. A wooden box of 4 $\mathrm{m} \times 2 \mathrm{~m} \times 0.46 \mathrm{~m}$ was constructed. This box was then place 0.2 $\mathrm{m}$ away from the force platform to given space to the subject for a drop landing. Weights were added to the carried box in increments of $0.5 \mathrm{~kg}$ according to the stated body weight percentages.

\section{Experimental Procedure}

Each of the subjects performed drop landings with three varied carrying loads three times randomly. The carrying load was normalized by each of the subjects body weight and increased from $10 \%, 15 \%$ to $20 \%$. To prevent injuries and ensure that they landed on the force platform each of the subjects participated in a warm up and practice of the drop landing. After each of the subjects wore the same shoes and black tights reflective markers were attached to the pelvis and lower limbs $<$ Figure 1>. Each of the subjects were instructed not to jump off the wooden box but to step off it. Each of the conditions were performed three times and data from 2 of the trials were used for the analysis.
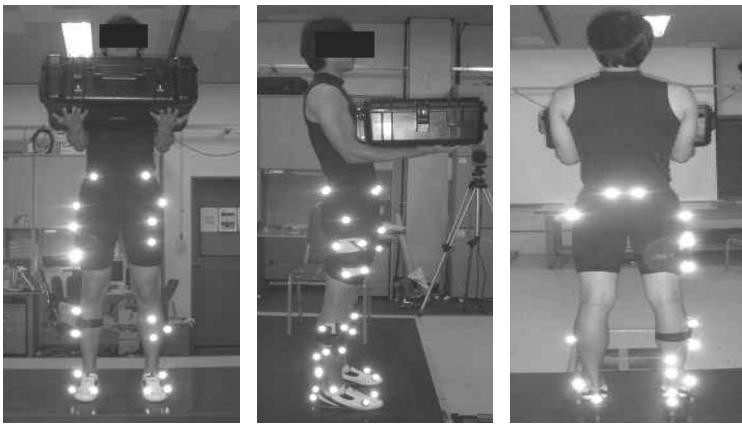

Figure 1. Reflective markers for lower body motion capture(CODA pelvis)

\section{Data Analysis}

The Qualisys Track Manager V2.3[build 482] program was used to calculate and gather the 3 dimensional coordinates of the reflective markers. Synchronized data was then exported as a C3D file to Visual3D Standard V4.75.14 and Matlab 2009(Mathworks, US) for the calculation of the needed variables The provided model was used by Visual3D for the CODA pelvis, thigh, shank and foot. The kinematic data was then filtered using a Butterworth low-pass filtering at $6 \mathrm{~Hz}$ and the joint angles were calculated using the Cardan Sequence(X-Y-Z) flexion/extension, adbuction/adduction and internal/external rotation. The lab coordinates were $X$ axis for the anteroposterior, $\mathrm{Y}$ axis for the mediolateral and $\mathrm{Z}$ axis for the vertical axis as shown in(Figure 2)(below). 

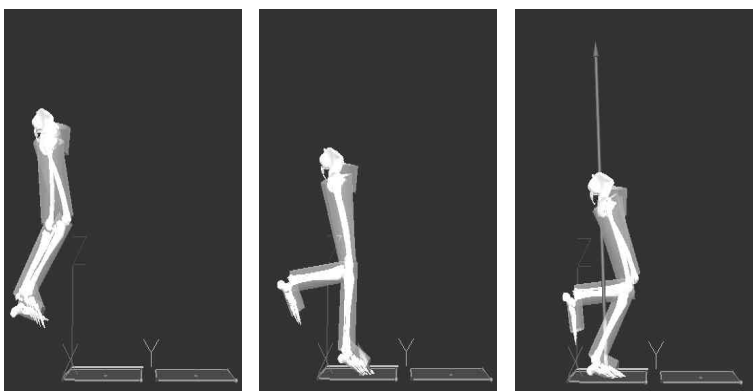

Figure 2. Series of pictures of the drop landing sequence

The RHO(Right Heel Off) was defined as the point where the right heel left the wooden box, and the RHC(Right Heel Contact) was defined as the first point the foot came in contact with the force platform. The max force was the maximum vertical ground force reaction, ST Max was the point after the landing when the propulsion phase was at a maximum, the min force was the minimum vertical force calculated between the Max force and the ST Max and the RTO(Right Toe Off) was when the subject stepped off the force platform with their right foot. These 6 events then divided the motion into 5 phases.

For the kinematic variables were calculated for the analysis were as follows; time for maximum flexion of the hip, knee and ankle, knee's ROM, hip's ROM, the hip, knee and ankle angle at $\mathrm{RHC}$, the time for RHC to the maximum knee flexion angle, and the time for RHC to the maximum plantar flexion angle. For the kinetics the impulse was calculated.

\section{Statistical Analysis}

The mean and the standard deviation of the kinematic and kinetic variables were calculated. Repeated One-Way ANOVA and Tukey post-hoc analysis was performed by the statistical program SPSS 18.0 with a significance level of $p<.05$.

\section{Results}

\section{Time Variables}

The time between events is shown in <Table 2>. There was a significant difference between the conditions for the time from maximum GRF to minimum $\mathrm{GRF}(p<.05)$. There was no significant difference to be observed for the time from RHC to the maximum GRF, and the RHC to the minimum GRF the start of the propulsion phase.

In <Table 3> there was a significant difference between the conditions for the time from the RHC to the maximum ankle angle. There was no significant difference between the conditions for the time from the RHC to the maximum knee angle.

\section{Maximum Flexion Angles and Angle at Contact}

There was no significant difference between the loading conditions for the time between the two events in(Table 3).

It was deemed that the load was not sufficient enough to affect the time of ankle and knee flexion. Likewise <Table $4>$ showed that there was no significant differences in the ankle, knee and hip maximum flexion angle at the RHC by the loading of the carried weights of $10 \%, 15 \%$ and $20 \%$ body weight.

Table 2. Time between events

(unit: sec)

\begin{tabular}{|c|c|c|c|c|c|}
\hline & & RHC and Max Force & Max Force and Min Force & Min Force and ST Max & ST Max and RTO \\
\hline Weight Percentage & $\mathrm{N}$ & $\operatorname{Mean}(\mathrm{SD})$ & Mean(SD) & Mean(SD) & $\operatorname{Mean}(\mathrm{SD})$ \\
\hline $10 \%$ & 18 & $.127(.024)$ & $.219(.042)$ & $.243(.070)$ & $.185(.034)$ \\
\hline $15 \%$ & 18 & $.116(.015)$ & $.243(.056)$ & $.244(.062)$ & $.189(.027)$ \\
\hline $20 \%$ & 18 & $.121(.026)$ & $.266(.053)$ & $.229(0089)$ & $.188(.029)$ \\
\hline F-value & & 1.127 & 3.842 & .210 & .097 \\
\hline$p$ & & .322 & $.028^{*}$ & .812 & .9070 \\
\hline
\end{tabular}


Table 3. Time between events

\begin{tabular}{cccc}
\hline & & $\begin{array}{c}\text { RHC and } \\
\text { Ankle Max Angle }\end{array}$ & $\begin{array}{c}\text { RHC and } \\
\text { Knee Max Angle }\end{array}$ \\
\hline $\begin{array}{c}\text { Weight } \\
\text { Percentage }\end{array}$ & $\mathrm{N}$ & Mean(SD) & Mean(SD) \\
\hline $10 \%$ & 18 & $.085(.031)$ & $.049(.012)$ \\
\hline $15 \%$ & 18 & $.097(.035)$ & $.049(.012)$ \\
\hline $20 \%$ & 18 & $.123(.042)$ & $.058(.024)$ \\
\hline F-value & & 4.988 & 1.455 \\
$p$ & $.011^{*}$ & .243 \\
\hline$* 0.05$ & &
\end{tabular}

Table 4. Comparison of maximum angle

\begin{tabular}{ccccc}
\hline \multicolumn{1}{c}{ Ankle } & Knee & Hip \\
\hline $\begin{array}{c}\text { Weight } \\
\text { Percentage }\end{array}$ & $\mathrm{N}$ & Mean(SD) & Mean(SD) & Mean(SD) \\
\hline $10 \%$ & 18 & -90.997 & 29.497 & 5.053 \\
\hline $15 \%$ & 18 & -90.105 & 29.260 & 4.268 \\
\hline $20 \%$ & 18 & -91.452 & 31.070 & 4.369 \\
\hline F-value & & .195 & .305 & .150 \\
$p$ & & .824 & .738 & .861 \\
\hline
\end{tabular}

\section{Joint Range of Motions}

The joint range of motions(ROM) for the hip, knee and ankle are shown in <Table 5>. There was no significant difference between the conditions for the joint ROM however the change in the ankle and knee were bigger than the hip joint ROM

Table 5. Joint angle at ground contact

(unit: deg)

\begin{tabular}{ccccc}
\hline & & Ankle & Knee & Hip \\
\hline \hline $\begin{array}{c}\text { Weight } \\
\text { Percentage }\end{array}$ & $\mathrm{N}$ & Mean(SD) & Mean(SD) & Mean(SD) \\
\hline $10 \%$ & 18 & $-86.844(5.552)$ & $26.146(7.766)$ & $4.745(4.837)$ \\
\hline $15 \%$ & 18 & $-85.733(5.101)$ & $25.625(6.450)$ & $4.057(4.045)$ \\
\hline $20 \%$ & 18 & $-85.814(6.053)$ & $26.575(6.061)$ & $4.145(4.463)$ \\
\hline F-value & & .222 & .088 & .127 \\
$p$ & .802 & .916 & .881 \\
\hline
\end{tabular}

\section{Impulse}

The impulse after the drop landing was calculated by integrating the force from the RHC until the maximum vertical ground reaction force and then was normalized according to the subjects individual body weight. The results are shown in <Table 6>. There is no statistically significant difference shown between the loading conditions. However, the impulse was largest for the $+10 \%$ body weight condition and then for the $20 \%$ and $15 \%$.

Table 6. Joint angle difference (unit: deg)

\begin{tabular}{ccccc}
\hline & & Ankle & Knee & Hip \\
\hline $\begin{array}{c}\text { Weight } \\
\text { Percentage }\end{array}$ & $\mathrm{N}$ & Mean(SD) & Mean(SD) & Mean(SD) \\
\hline $10 \%$ & 18 & $-4.277(1.736)$ & $3.576(1.455)$ & $.325(.274)$ \\
\hline $15 \%$ & 18 & $-4.305(1.764)$ & $3.711(1.825)$ & $.406(.538)$ \\
\hline $20 \%$ & 18 & $-5.568(2.523)$ & $4.462(2.534)$ & $.368(.322)$ \\
\hline F-value & & 2.350 & 1.458 & .168 \\
$p$ & & .106 & .242 & .831 \\
\hline
\end{tabular}

Table 7. Impulse

(unit: $\mathrm{Nm} / \mathrm{BW}$ )

\begin{tabular}{ccccccc}
\hline $\begin{array}{c}\text { Weight } \\
\text { Percentage }\end{array}$ & $\mathrm{N}$ & $10 \%$ & $15 \%$ & $20 \%$ & F-value & $p$ \\
\hline \hline $\begin{array}{c}\text { Mean } \\
(S D)\end{array}$ & 18 & $\begin{array}{c}1.193 \\
(.188)\end{array}$ & $\begin{array}{c}1.074 \\
(.125)\end{array}$ & $\begin{array}{c}1.104 \\
(.225)\end{array}$ & 2.037 & .141 \\
\hline
\end{tabular}

\section{Discussion}

There are many studies that deal with the drop landing, however most of the research has only investigated simply one foot and two foot landing and has not accounted for various loading carrying conditions. This study analyzes the kinetic and kinematic variables according to three various $\operatorname{loads}(10 \%, 15 \%, 20 \% \mathrm{BW})$ that are anteriorly carried. It focus in on time related factors, joint angles maximums and ROM and impulses. This study showed that there was a significant difference in the time of the phases.

It is reported by Choi et al.(2006) That there are two strategies for person to recover from a drop landing; first, to use the landing leg to attenuate the shock by trying to increase the time, and second, is to try to decrease the time and transfer the weight to the other leg as quickly as possible. During the drop landing, the time from the RHC to maximum ankle dorsal flexion the loading of the plus $20 \%$ body weight condition was the longest. As the loading increased it was observed that subject reacted by increasing the time for the maximum dorsal flexion more than the time for the maximum knee flexion. Also likewise this trend could be seen comparing the hip and knee time to maximum flexion as opposed 
to the ankle time to maximum flexion. There was a significant difference between the time of the phase from the maximum GRF to the minimum GRF. As the loading increased it was seen that there was a difference in the time for the reaction force to be reduced. This increase of time to dissipate the high ground reaction forces could be understood as having a negative effect on the lower extremities.

There was no significant difference shown between the conditions for the ankle, knee and hip maximum flexion angles and the angle at landing. After observing the phase from the RHC to the maximum flexion angle the change in the ankle joint is most substantial, then the knee and the hip angle. This data can show that the subjects strategy to attenuate the increasing shock from the higher loading is to primarily use the ankle joint then to use the knee and finally the hip.

Schmitz et al.(2007) states that men use injure their ankle joint as they use it to attenuate the shock at drop landing while women use their knee and so are at a higher risk then men for anterior and posterior cruciate ligament injuries. As this strategy for disapating higher loads, i.e. women use their knee and tend to injure their knee while men use their ankle and thus tend to injury their ankle, can show that their strategies are overloading their joints and this is why they suffer injuries. The results of study agrees with Schmitz and colleagues research as the higher the loading the more the ankle ROM is employed by the subjects. Our results show for male subjects, it is better for both high and low drop landings to prevent injury, that they should use their knee joints and thus not be overloading their ankle joint to attenuate the increase shock.

According to at landing a high flexion of the knee joint helped to reduce the risk of injury to the lower extremities. However in our study, we showed that as the loading increased it was not the knee flexion angle that increased but the dorsal flexion angle of the ankle increased. We think that at landing for more effective landing it is better to use the larger motion of the knee flexion than the ankle flexion. The results showed that even though the ROM of the knee was smaller than the ROM of the ankle, it did increase as the loading increased. There was no significant difference for the ROM of the hip joint ankle between the loading conditions. From this it was judged that the ankle and the knee joints tended to attenuate the majority of the shock and thus their was not much effect at the hip joint. By this logic it can be recommended that for the prevention of injuries from drop landings while carrying a load that flexibility and strength of the knee and ankle joints are of paramount importance.
There has been research investigating the difference in gender of players that participate in sports with double feet drop landing, high jumping, frequent landing techniques(basketball, etc.) have been carried out(Zhang et al., 2000; McNitt-Gray, 1993). McNitt-Gray(1993) has reported on the energy absorption strategy of players dropping down from a height of $0.3 \mathrm{~m}$ on one foot, and Schmitz et al.(2007) has reported on double feet drop landing from a height of $0.6 \mathrm{~m}$. For the one legged drop landing the strategy of using the ankle was the most popular and between $78.2 \%$ to $88.3 \%$ of the shock absorbed was by the ankle joint. For the double foot drop landing from a height of $0.6 \mathrm{~m}$ shock absorbtion was shown for the ankle joint to be between $21 \%$ to $43 \%$. This difference in single legged and double legged strategy is because of the difference of width of support between single and double footed landing(Zhang et al., 2000; Schot, Bates \& Dufek, 1994). This is explained by the increase in the base of stability at landing reduces the dependancy on the ankle joint as the knee joint can then contribute more. As the loading condition increased there was a decrease in the stability and as a result the impulse increased but only an insignificant amount.

In $<$ Figure $3>$ the time for the RHC to the maximum ground reaction force is shown. In general injury depends on the anatomical structure, the magnitude of the load and the rate of the loading which is dependant on the time(Cho et al., 2010). In this study there was no significant difference between the impulse and the maximum vertical ground reaction forces. The results show that the higher the loading the shorter time for the impulse peak to occur. With the increased loading rates at the increased loading conditions it can be suggested that to reduce the risk of injury the subject should try to reduce the speed of their COM by trying to use both their ankle and knee joints. However in one footed drop landing it is difficult

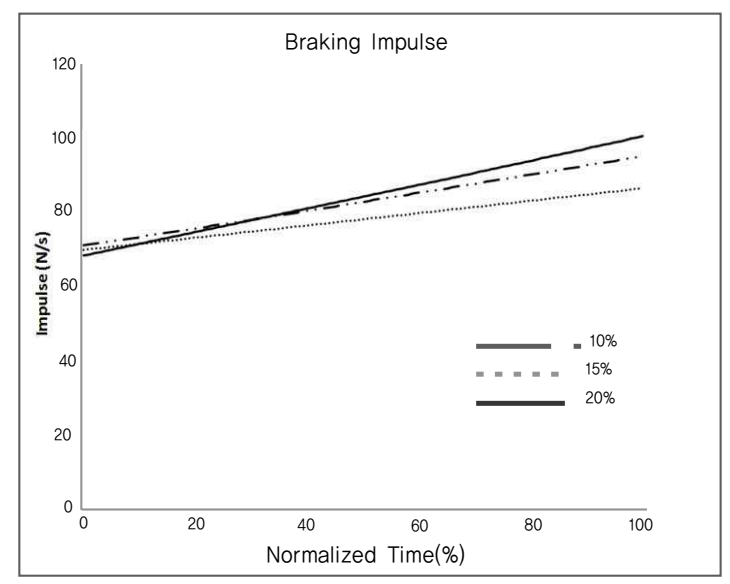

Figure 3. Impulse Force according to the loads(10\%, 15\%, 20\% BW) 
for a subject to use their knee joint to reduce the risk of injury because it is difficult to balance for an extended period of time.

\section{Conclusion}

The purpose of this study was to analyze kinetic and kinematic variables of a drop landing on one leg with varying loads. The results are as follows:

1. There is a significant difference between the time from the RHC to the maximum flexion of the ankle according to the loading conditions.

2. For each of the subjects at the drop landing there was a trend of more movement for the ankle joint than the knee and hip joints as the loading increased.

3. As the loading increased the impulse time became quicker.

In conclusion as the upper body carrying load increased the mechanism of injury can be shown. The main shock absorbers for the landing impact of the drop landing are the ankle and knee joints and the balance of load bearing between them is vital for the stability at landing and safety. In this study it can be observed of the one legged drop landing the higher the carrying loads the more the load on the ankle joint occurs as opposed to the knee joint. Consequently a subject in order to prevent injury must be able to use not only the ankle but the knee joint as well as a shock absorber.

It is recommended in future that studies should be carried out to investigate the effects of even higher loading conditions to find a threshold of when the ankle joint becomes overloaded. Also the relationship between ankle dorsal and flexors strength and prevention of injury needs to be undertaken.

\section{References}

Cho, J. H., Kim, K. H., Moon, G. S., Cho, Y. J., \& Lee, S, C.(2010). Analysis of Injury Mechanism on Ankle and Knee during Drop Landings According to Landing Directions. Korean Journal of Sports Biomechanics, 20(1), 67-73.

Choi, C. S., Nam, K. J., Shin, I. S., Seo, J. S., Eun, S. D., \&
Kim, S. B.(2006). Shock Attenuation Mechanism in Drop Landing According to the Backpack Weight Changes. Korean Journal of Sports Biomechanics, 16(2), 25-35.

Dufek, J. S., \& Bates, B. T.(1991). Biomechanical factors associated with injury during landing in jump sports. Sports Medicine, 12(5), 326-37.

Decker, J. M., Torry, R. M., Wyland, J. D., Steret, I. W., \& Steadman, J. R.(2003). Gender differences in lower extremity kinematics, kinetics and energy absorption during landing. Clinical Biomechanics, 18(7), 662-669.

Devita, P., \& Skelly, W. A.(1992). Effect of landing stiffness on joint kinetics and energetics in the lower extremity. Medicine and Science in Sports and Exercise, 24(1), $108-115$.

Herrington, L., \& Munro, A.(2010). Drop jump landing knee valgus angle; normative data in a physically active population. Physical Therapy in Sport, 11, 56-59

Hong, S. P., Kwon, Y. L., \& Lee, S. H.(1991). Effect of load changes of upper part of human body on respones to walking gait. The Korean Journal of Physical Education, 30(1), 1377-1388.

Hewett, T. E., Myer, G. D., Ford, K. R., Heidt, R. S., Colosimo, A. J., Scoot, G. M, Bogert, A. J., Paterno, M. V., \& Succop, P.(2005), Biomechanical measures of neuromuscular control and valgus loading of the knee predict anterior cruciate ligament injury risk in female athletes. American Journal of Sports Medicine, 33(4), 492-501.

Jo, S. C.(2004). The Effect of Blindfolded Eyes of Kinematics of Drop Landing. The Korean Journal of Physical Education, 43(3), 851-860.

Jo, S. C., \& Chea, J. R.(1998). Kinematic and Kinetic Analysis of Drop Landing. The Korean Journal of Sports Medicine, 16(2), 330-340.

Kim, H. J., Kim, J. D., \& Kim, M. Y.(2010). Effects of female maturation on the Lower extremity injury risk factors during the box drop Landing. The Korean Journal of Physical Education, 49(1), 437-443.

Kulas, A., Zalewski, P., Tibor Hortobagyi., \& Devita, P.(2008). Effects of added trunk load and corresponding trunk position adaptations on lower extremity biomechanics during drop-landings. Journal of Biomechanics, 41(1), 180-185

Lee, S. Y., Lee, S. M., \& Choi, J. Y.(2001). The influence of 
landing style on the shock-absorbing mechanism of the lower extremity. Korean Journal of Sports Biomechanics, 10(2), 77-97.

Mascaro, T. B., \& Swanson, L. E.(1994). Rehabilitation of the foot and ankle. Orthopedic Clinics of North America, 25(1), 147-60.

McNitt-Gray, J. L.(1993). Kinetics of the lower extremities during drop landings from three heights. Journal of Biomechanics, 26(9), 1037-1046.

Pollard, C. D., Sigward, S. M, \& Powers, C. M.(2010). Limited hip and knee flexion during landing is associated with increased frontal plane knee motion and moments. Clinical Biomechanics, 25(2), 142-146.

Schmitz, R. J., Kulas, A. S., Perrin, D. H., Riemann, B. L., \& Schultz, S. J.(2007). Sex differences in lower extremity biomechanics during single leg landings. Clinical Biomechanics, (22)6, 681-688.

Schot, P. K., Bates, B. T., \& Dufek, J. S.(1994). Bilateral performance symmetry during drop landing: a kinetic analysis. Medicine and Science in Sports and Exercise, 26(9), 1153-1159.

Yang, C. H., Guo, L. Y., Tsao, H., Deng, H. L., \& Gong, W. Y.(2007). Changes in lower limb muscle activations in individuals with functional ankle instability during drop landings. Journal of Biomechanics, 40(2), 670.

Yeow, C. H., Lee, P. V. S., \& Goh, J. C. H.(2009). Effect of landing height on frontal plane kinematics, kinetics and energy dissipation at lower extremity. Journal of Biomechanics, 42(12), 1967-1973.

Yu, Y. J., \& Lim, B. O.(2008). Characteristics of drop Landing from different heights in children with down syndrome. The Korean Journal of Physical Education, 47(3), 547-554.

Zhang, S. N., Bates, B. T., \& Dufek, J. S.(2000). Contributions of lower extremity joints to energy dissipation during landings. Medicine and Science in Sports and Exercise, 32(4), 812-819. 